Jurnal Keperawatan Silampari

Volume 5, Nomor 1, Desember 2021

e-ISSN: 2581-1975

p-ISSN: 2597-7482

DOI: https://doi.org/10.31539/jks.v5i1.2971

\title{
BRIEF BEHAVIORAL TREATMENT TERHADAP KUALITAS TIDUR PASIEN CONGESTIVE HEART FAILLURE
}

\author{
Ahmad Redho ${ }^{1}$, Dina Rahmawati ${ }^{2}$, Sapriyanti $^{3}$, \\ Wati Jumaiyah ${ }^{4}$, Abdul Rahim Kamil ${ }^{5}$ \\ Sekolah Tinggi Ilmu Kesehatan Al Insyirah ${ }^{1}$ \\ Universitas Muhammadiyah Jakarta $2,3,4,5$ \\ Ahmadredho49@gmail.com ${ }^{1}$
}

\begin{abstract}
ABSTRAK
Penelitian ini bertujuan untuk mengetahui pengaruh terapi Behavioral Therapy Intervensi (BBT-I) terhadap kualitas tidur pada pasien CHF (Congestive Heart Failure) berdasarkan hasil riset terkini (Evidence Based Nursing Practice). Penelitian ini menggunakan metode eksperimental dengan desain eksperimental 2 group pre-test dan post-test. Hasil penelitian didapatkan karakteristik responden berdasarkan jenis kelamin pada kelompok kontrol dan intervensi dari 12 pada kelompok kontrol sebagian besar perempuan yaitu sebanyak 7 orang $(58,3 \%)$. Sedangkan pada kelompok intervensi sebagian besar berjenis kelamin perempuan dan laki-laki masing-masing yaitu sebanyak 6 orang (50,0\%). Terapi Behavioral Therapy for Insomnia (BBT-I) berpengaruh terhadap kualitas tidur pada pasien CHF (Congestive Heart Failure) dan sesuai dengan hasil riset terkini (Evidence Based Nursing Practice) Pelaksanaan therapy BBT-I pada pasien CHF grade 1-II dengan gangguan tidur stabil. Pelaksanaan therapy BBT-I pada pasien CHF grade I-II stabil dengan gangguan tidur cukup memberikan pengaruh dan meningkat kulitas tidur. Hasil penelitian terapi Behavioral Therapy for Insomnia (BBT-I) berpengaruh terhadap kualitas tidur pada pasien CHF (Congestive Heart Failure) dan sesuai dengan hasil riset terkini (Evidence Based Nursing Practice). Simpulan, terapi Behavioral Therapy for Insomnia (BBT-I) berpengaruh terhadap kualitas tidur pada pasien CHF (Congestive Heart Failure).
\end{abstract}

Kata Kunci: Brief Behavioral Treatment, Congestive Heart Failure, Kualitas Tidur

\begin{abstract}
This study aims to determine the effect of Behavioral Therapy Intervention (BBT-I) on sleep quality in CHF (Congestive Heart Failure) patients based on the results of the latest research (Evidence-Based Nursing Practice). This study used an experimental method with a practical design of 2 groups, pre-test, and post-test. The research results on the characteristics of respondents based on gender in the control group and the intervention of the 12 control groups were primarily women, as many as seven people (58.3\%). While in the intervention group, most of them were female and male, each of which was six people (50.0\%). Behavioral Therapy for Insomnia (BBT-I) affects the sleep quality of CHF (Congestive Heart Failure) patients. It follows the latest research results (Evidence-Based Nursing Practice) Implementation of BBT-I therapy in CHF grade 1-II patients with stable sleep disorders. Implementing BBT-I treatment in regular CHF grade I-II patients with adequate sleep disturbances affects and improves sleep quality. The results of Behavioral Therapy for Insomnia (BBT-I) research affect the sleep quality of CHF (Congestive Heart
\end{abstract}


Failure) patients. They are by the latest research results (Evidence-Based Nursing Practice). In conclusion, Behavioral Therapy for Insomnia (BBT-I) affects the sleep quality of CHF (Congestive Heart Failure) patients.

Keywords: Brief Behavioral Treatment, Congestive Heart Failure, Sleep Quality

\section{PENDAHULUAN}

Data WHO tahun 2015 menunjukkan bahwa 70\% kematian di dunia disebabkan oleh penyakit tidak menular (39,5 juta dari 56,4 kematian). Dari seluruh kematian akibat Penyakit Tidak Menular (PTM) tersebut, 45\% nya disebabkan oleh penyakit jantung dan pembuluh darah, yaitu 17.7 juta dari 39,5 juta kematian menunjukkan prevalensi penyakit jantung berdasarkan diagnosis dokter di Indonesia sebesar 1,5\%, dengan peringkat prevalensi tertinggi (Riskesdas, 2018).

World Health Organization (WHO) tahun 2016 menunjukkan pada tahun 2015 terdapat 23 juta atau sekitar 54\% kematian yang disebabkan oleh Congestive Heart Failure (CHF). Peradaban dunia, kemajuan teknologi, semakin meningkatnya kemakmuran, pertumbuhan ekonomi berpengaruh terhadap kejadian dan jenis penyakit. Hal tersebut menyebabkan jenis penyakit yang beragam salah satunya congestive heart Real In Nursing Journa (RJN). Hasil penelitian Hartati (2019) ditemukan setengah klien congestive heart failure pada kategori buruk yaitu sebanyak 14 orang dari 20 0rang (70.0\%). Pasien dengan congestive heart failure sulit tidur dikarenakan beberapa alasan diantaranya sesak nafas yang dirasakan saat berbaring, nyeri dada, lingkungan yang tidak nyaman seperti lingkungan yang tidak kondusif dan kurang nya pengawasan jumlah pengunjung yang datang sehingga mengganggu istirahat klien.

Pada pasien dengan gagal jantung akan terjadi edema pulmonal yang dapat menurunkan elastisitas paru dan meningkatkan kerja pernafasan sehingga pasien mengalami dyspnoe, Orthopnoe/NPD (Dipsnoe Noktural Paroksimal) yang akan terasa enak dalam posisi duduk, batuk, dan hal ini dapat menyebabkan kesulitan tidur yang akhirnya menimbulkan gangguan tidur (Sari et al., 2019). Berbagai gejala klinis pada penderita gagal jantung kanan diantaranya; dipsnea, ortopnea, pernapasan cheyne-stokes, Paroxysmal Nocturnal Dyspnea (PND), asites, piting edema, berat badan meningkat, dan sesak nafas sehingga menggangu tidur pada malam hari (Handayani, 2020).

Para peneliti telah mendokumentasikan tingginya tingkat gangguan tidur yang dilaporkan sendiri di antara pasien HF, dengan tingkat mulai dari 35\% hingga 70\% pada pasien HF. Gagal jantung dikaitkan dengan insomnia dalam penelitian terhadap pasien dengan penyakit kronis, dan kualitas tidur lebih buruk pada pasien kardiomiopati dilatasi, di antaranya $40 \%$ menderita gagal jantung dibandingkan pada populasi umum. Tidak ada perbedaan gangguan tidur antara pasien gagal jantung sistolik dan diastolik, dan kelas asosiasi jantung New York dan fraksi ejeksi ventrikel kiri tidak membedakan orang dengan dan tanpa gangguan tidur. Kesulitan memulai dan mempertahankan tidur, umumnya terkait dengan insomnia, sering terjadi pada orang dengan gagal jantung. Antara 23\% dan 47\% pasien gagal jantung melaporkan kesulitan tidur atau latensi tidur yang lama (durasi waktu dari waktu tidur hingga onset tidur). Terapi tanpa obat-obatan medis bisa diterapkan pada insomnia tipe primer maupun sekunder. Banyak peneliti menyarankan terapi tanpa medikamentosa pada penderita insomnia karena tidak memberikan efek samping dan juga memberi kebebasan kepada therapis dan penderita untuk menerapkan terapi sesuai keadaan penderita.Terapi tipe ini sangat memerlukan kepatuhan dan kerjasama penderita dalam 
mengikuti segala nasehat yang diberikan oleh terapis diantaranya stimulus control, sleep restriction, dan sleep hygine.

Data pendahuluan di Rumah Sakit Umum Tarakan menunjukkan bahwa tingkat gangguan kualitas tidur pada pasien gagal jantung yang melakukan tindakan keperawatan non farmakologis yaitu dengan brief behavior therapy yang masih relatif rendah dimana intervensinya dengan memodifikasi perilaku bangun kita dapat memiliki dampak langsung pada dua sistem fisiologis utama yang mengatur tidur, penggerak homeostatis dan sirkadian. Berfokus pada memberikan heuristik yang berguna untuk menjelaskan alasan pengobatan kepada pasien dan terapis. Dorongan tidur homeostatis mengacu pada peningkatan kecenderungan untuk tidur dengan meningkatnya durasi terjaga. Penggerak sirkadian mengacu pada variasi dalam otak dan proses biologis yang diatur oleh alat pacu jantung pusat jam biologis.

Penelitian telah menemukan terapi perilaku pada banyak kasus, lebih efektif dari pada obat untuk gangguan tidur. Di orang dewasa yang lebih tua yang berisiko lebih besar untuk mengalami efek samping serius yang berkaitan dengan farmakoterapi untuk insomnia dan yang sering berisiko lebih besar untuk mengalami polifarmasi, pendekatan nonfarmakologis harus menjadi yang pertama pilihan pengobatan dipertimbangkan. Cognitive Behavioral Therapy (CBT) untuk insomnia telah terbukti memiliki kemanjuran jangka pendek dan jangka panjang pada orang dewasa yang lebih muda dan lebih tua. Pendekatan ini menggabungkan kontrol stimulus dan atau pembatasan tidur dengan restrukturisasi kognitif, kebersihan tidur yang baik (satu set pedoman untuk kebisaaan tidurbangun yang sehat), dan relaksasi. Program dari CBT biasanya terdiri dari 6-10 sesi mingguan yang dikelola oleh khusus dokter terlatih. Brief Behavoural Therapy for Insomnia (BBTI) memiliki fokus perilaku eksklusif, komponen inti adalah kontrol stimulus dan pembatasan tidur. Beberapa uji acak dilakukan dan menunjukkan BBTI efektif pada orang dewasa (Apriliani \& Soetjipto, 2020).

Mengoptimalkan proses ini memfasilitasi permulaan tidur, meningkatkan konsolidasi tidur. Banyak program perawatan BBT-I untuk gangguan tertentu telah dievaluasi keberhasilan therapy yaitu dengan menitik beratkan pada pengendalian stimulus dan teknik pembatasan tidur serta mendidik pasien tentang praktik dan perilaku. Bulan November 2020 peneliti melakukan wawancara dan observasi kepada empat orang pasien yang sedang dirawat, informasi yang didapatkan rata-rata usia pasien 50- 60 tahun, sudah pernah dirawat dengan penyakit yang sama.

Hasil wawancara tersebut didapati rata-rata pasien gagal jantung merasa sesak bila malam hari, cepat lelah, dua pasien mengatakan tidak masalah dengan tidurnya, satu pasien menyatakan masalah tidurnya karena sesak dan berisik, untuk kecemasan satu pasien merasa cemas bila timbul sesak, satu pasien mengatakan pasrah saja, selain itu pasien juga merasa nyaman bila ada keluarga yang menunggu. Fenomena yang terjadi pada pasien gagal jantung yang menjalani perawatan di Rumah Sakit Tarakan Jakarta adanya ketidak samaan keluhan. Seperti ada yang mengalami PND, pasien yang cemas, dan ada pasien yang kualitas tidurnya terganggu. Adapun tujuan untuk mengevaluasi implementasi perawat dan upaya yang sudah dilakukan pasien gagal jantung dengan grade I dan II dengan cara menggunakan BBTI untuk meningkatkan kualitas tidur.

Gagal jantung merupakan keadaan patofisiologik, ditandai dengan memburuknya kondisi kesehatan sampai beberapa hari atau minggu bahkan dapat berbulan-bulan, dengan manifestasi klinis fatigue, sesak nafas, Paroxysmial Nocturnal Dyspnea (PND), kondisi tersebut semakin memburuk jika gangguan pemenuhan kualitas tidur tidak dapat diatasi dengan baik, apabila tidak ada kerja sama antara perawat dan pasien, untuk itu perlunya 
implementasi keperawatan dan upaya yang dilakukan pasien agar dapat meningkatkan kualitas tidur. Jumlah pasien rawat di Rumah Sakit Tarakan Jakarta dengan gagal jantung pada tahun 2020 yang tercatat berjumlah 3045 pasien (Data RSUD Tarakan, 2020). Hasil wawancara dengan tiga perawat mengatakan fenomena yang terjadi adalah pasien yang dirawat dengan gagal jantung, rata-rata pasien dengan gagal jantung mengalami gangguan tidur.

Memberikan intervensi ini dengan tatap muka secara langsung dengan pasien dan mengguankan alat komunikasi jarak jauh sehingga komunikasi dan progres dari perkembangan pasien tetap terpantau. Selain itu, fokus pada penelitian ini adalah intervensi BBT-T yang masih jarang sekali digunakan khususnya di tempat penelitian.

\section{METODE PENELITIAN}

Penerapan EBP ini dilakukan dengan tujuan melakukan intervensi BBTI adalah memodifikasi prilaku bangun yang memberikan dampak langsung sistem fisiologis dengan menggunakan tiga prinsip yaitu pengontrolan stimulus, membatasi tidur, intervensi untuk gangguan tidur primer atau gangguan tidur dengan hal pemberat lainnya. Dengan menggunakan desain Randomized Controlled Trial (RCT) dengan two group pre-test dan post-test dengan kriteria pasien CHF yang ada gangguan tidur dan usia di atas 18 tahun.

\section{HASIL PENELITIAN \\ Karakteristik Responden}

Tabel. 1

Karakteristik Responden Berdasarkan Jenis Kelamin

Responden Kelompok Kontrol dan Intervensi $(n=25)$

\begin{tabular}{lcccc}
\hline \multirow{2}{*}{ Jenis Kelamin } & \multicolumn{5}{c}{ Kelompok } \\
\cline { 2 - 5 } & \multicolumn{3}{c}{ Kontrol } & Intervensi \\
\cline { 2 - 5 } & $\mathrm{F}$ & $\%$ & 6 & f \\
\hline Perempuan & 7 & 58,3 & 6 & 50,0 \\
Laki-Laki & 5 & 41,7 & 12 & 50,0 \\
\hline Total & 12 & 100 & & 100 \\
\hline
\end{tabular}

Berdasarkan table 1 menunjukan karakteristik responden berdasarkan jenis kelamin pada kelompok kontrol dan intervensi dari 12 pada kelompok kontrol sebagian besar perempuan yaitu sebanyak 7 orang $(58,3 \%)$. Sedangkan pada kelompok intervensi sebagian besar berjenis kelamin perempuan dan laki-laki masing-masing yaitu sebanyak 6 orang $(50,0 \%)$.

\section{Uji Homogenitas Responden Berdasarkan Jenis Kelamin pada Kelompok Kontrol dan Intervensi}

Tabel. 2

Uji Homogenitas Berdasarkan Jenis Kelamin Responden pada Kelompok Kontrol dan Intervensi

\begin{tabular}{cccc}
\hline Levene Statistic & df1 & df2 & $\mathrm{p}$ \\
\hline 0,314 & 1 & 22 & 0,581 \\
\hline
\end{tabular}


Berdasarkan tabel 2 menunjukan hasil uji hemogenitas karakteristik responden jenis kelamin $\mathrm{p}=0,581$, artinya karakteristik responden jenis kelamin pada kelompok kontrol dan intervensi adalah sama atau tidak ada perbedaan.

\section{Karakteristik Responden Berdasarkan Usia}

Tabel. 3

Karakteristik Responden Berdasarkan Usia Responden Kelompok Kontrol dan Kelompok Intervensi

\begin{tabular}{lllccc}
\hline Kelompok & $\mathrm{N}$ & Mean & $\mathrm{SD}$ & Nilai Min & Nilai Maks \\
\hline Kontrol & 12 & 52,67 & 5,314 & 45 & 60 \\
Intervensi & 12 & 42,83 & 5,670 & 45 & 60 \\
\hline
\end{tabular}

Berdasarkan tabel 3 menunjukan karakteristik responden usia pada kelompok kontrol dan intervensi dari 12 responden diperoleh nilai rata-rata pada kelompok kontrol 52,67 dengan nilai simpangan baku 5,314. Adapun nilai rata-rata kelompok intervensi adalah sebesar 42,83 dengan simpangan baku 5,670.

\section{Uji Homogenitas Responden Berdasarkan Usia pada Kelompok Kontrol dan Intervensi}

Tabel. 4

Uji Homogenitas Berdasarkan Usia Responden pada Kelompok Kontrol dan Intervensi

\begin{tabular}{cccc}
\hline Levene Statistic & $\mathrm{df} 1$ & $\mathrm{df} 2$ & $\mathrm{p}$ \\
\hline 0,182 & 1 & 22 & 0,674 \\
\hline
\end{tabular}

Berdasarkan tabel 4 menunjukan hasil uji hemogenitas karakteristik responden usia $\mathrm{p}=0,674$, artinya karakteristik responden usia pada kelompok kontrol dan intervensi adalah sama atau tidak ada perbedaan.

Tabel. 5

Karakteristik Responden Berdasarkan Tingkat Pendidikan

Responden Kelompok Kontrol dan Kelompok Intervensi

\begin{tabular}{|c|c|c|c|c|}
\hline \multirow{3}{*}{ Pendidikan } & \multicolumn{4}{|c|}{ Kelompok } \\
\hline & \multicolumn{2}{|c|}{ Kontrol } & \multicolumn{2}{|c|}{ Intervensi } \\
\hline & $\mathrm{F}$ & $\%$ & $\mathrm{f}$ & $\%$ \\
\hline SD & 3 & 25,0 & 4 & 33,3 \\
\hline SMP & 6 & 50,0 & 6 & 50,0 \\
\hline SMA & 3 & 25,0 & 1 & 8,3 \\
\hline PTD & 0 & 0 & 1 & 8,3 \\
\hline Total & 12 & 100 & 12 & 100 \\
\hline
\end{tabular}

Berdasarkan tabel 5 menunjukan karakteristik responden tingkat pendidikan pada kelompok kontrol dan intervensi dari 12 responden sebagian besar pada kelompok kontrol berpendidikan SMP yaitu sebanyak 6 orang (50,0\%). Sedangkan pada kelompok intervensi sebagian besar berpendidikan SMP yaitu masing-masing sebanyak 6 orang $(50,0 \%)$. 


\section{Uji Homogenitas Responden Berdasarkan Tingkat Pendidikan pada kelompok Kontrol dan Intervensi}

Tabel. 6

Uji Homogenitas Berdasarkan Tingkat Pendidikan Responden pada Kelompok Kontrol dan Intervensi

\begin{tabular}{lccc}
\hline Levene Statistic & df1 & df2 & p \\
\hline 0,219 & 1 & 22 & 0,644 \\
\hline
\end{tabular}

Berdasarkan tabel 6 menunjukan hasil uji hemogenitas karakteristik responden tingkat pendidikan $\mathrm{p}=0,644$, artinya karakteristik responden tingkat pendidikan pada kelompok kontrol dan intervensi adalah sama atau tidak ada perbedaan.

\section{Karakteristik Responden Berdasarkan Lama Terakhir Dirawat atau Berobat}

Tabel. 7

Karakteristik Responden Berdasarkan Lama Terakhir Dirawat atau Berobat Responden Kelompok Kontrol dan Intervensi

\begin{tabular}{lcccc}
\hline & \multicolumn{4}{c}{ Kelompok } \\
\cline { 2 - 5 } Lama Terakhir Dirawat atau Berobat & \multicolumn{3}{c}{ Kontrol } & \multicolumn{2}{c}{ Intervensi } \\
\cline { 2 - 5 } & $\mathrm{F}$ & $\%$ & $\mathrm{f}$ & $\%$ \\
\hline$<6$ Bulan & 4 & 33,3 & 5 & 41,7 \\
$>6$ Bulan & 8 & 66,7 & 7 & 58,3 \\
\hline Total & 12 & 100 & 12 & 100 \\
\hline
\end{tabular}

Berdasarkan tabel 7 menunjukan karakteristik responden lama terakhir dirawat atau berobat pada kelompok kontrol dan intervensi dari 12 responden sebagian besar pada kelompok kontrol $>6$ bulan yaitu sebanyak 8 orang $(66,7 \%)$. Sedangkan pada kelompok intervensi sebagian besar $>6$ bulan yaitu sebanyak 7 orang $(58,3 \%)$.

\section{Uji Homogenitas Responden Berdasarkan Lama Terakhir Dirawat atau Berobat pada kelompok Kontrol dan Intervensi}

Tabel. 8

Uji Homogenitas Berdasarkan Lama Terakhir Dirawat atau Berobat pada Kelompok Kontrol dan Intervensi

\begin{tabular}{lccc}
\hline Levene Statistic & df1 & df2 & p \\
\hline 0,607 & 1 & 22 & 0,444 \\
\hline
\end{tabular}

Berdasarkan tabel 8 menunjukan hasil uji hemogenitas karakteristik responden lama terakhir dirawat atau berobat $\mathrm{p}=0,444$, artinya karakteristik responden lama terakhir dirawat atau berobat pada kelompok kontrol dan intervensi adalah sama atau tidak ada perbedaan.

\section{PEMBAHASAN}

BBT merupakan pengembangan dari metode CBT, BBTI telah menunjukkan kemanjuran dalam mengobati orang dewasa dimana setelah dilakukan BBTI dalam waktu empat minggu ditemukan adanya penurunan gangguan tidur. CBT mempunyai empiris 
untuk intervensi perilaku. Kunci utama brief behavior adalah gunakan konseptual kognitif dan fokus selama therapy. Semenara BBTI tidak berbeda dari CBTI pada kunci hasil mialnya isi, buku harian, respon/remisi (McCrae et al., 2018).

Hasil dari pengukuran menggunakan PSQI didapatkan hasil bahwa umur 45-60 tahun menderita CHF dan mengalami gangguan tidur. Gagal jantung disebabkan karena jantung tidak mampu membawa darah secara efektif untuk kebutuhan metabolik, karena adanya disfungsi bilik jantung yang biasanya terjadi karena adanya aritmia dan karena kelebihan cairan sehingga menyebabkan perubahan fungsi jantung. Penderita gagal jantung akan merasa mudah lelah, orthopnea, dan edema, hal ini bias terjadi karena penderita jantung kurang memahami perawatan mandiri (self care) (Anggraheni, 2019).

Jenis kelamin yang mempunyai resiko tinggi untuk mengalami gagal jantung kongestif adalah perempuan. Pada Penelitian studi dan direktur public health research di the Smidt Heart Institute, mengonfirmasi perempuan secara biologis dan fisiologis berbeda dengan pria, perempuan lebih rentan terkena empat tipe penyakit kardiovaskular, berdasarkan data berbasis komunitas yang dikumpulkan dari berbagai laman di seluruh negeri. Data tersebut mewakili hampir 145.000 pengukuran tekanan darah selama periode 43 tahun, dari 32.833 peserta studi yang berusia antara 5-98 tahun. Karena risiko terkena serangan jantung, gagal jantung, atau stroke biasanya dimulai dengan tekanan darah tinggi, dari pola peningkatan tekanan darah. Pada pendekatan ini peneliti mengidentifikasi perkembangan dan evolusi fungsi vaskular wanita sangat berbeda dari pada pria. Faktanya, wanita menunjukkan tanda-tanda peningkatan tekanan darah jauh lebih awal dari pria. Maka didefinisikan ambang hipertensi dengan cara yang sama persis, seorang wanita berusia 30 tahun dengan tekanan darah tinggi mungkin lebih berisiko mengalami penyakit kardiovaskular dari seorang pria dengan tekanan darah tinggi pada usia yang sama, kata Susan Cheng (WBP, 2020).

Kualitas tidur pasien CHF grade 1- III di RSUP Tarakan Jakarta diukur menggunakan kuesioner PSQI yang dapat menyatakan baik atau buruknya kualitas tidur. Dari dua kali pengambilan data yang dilakukan pada kelompok kontrol pada awal minggu ke-1 didapatkan nilai rata-rata kualitas tidur 9,08. Sedangkan pada minggu ke-4 nilai rata nilai rata-rata kualitas tidur 8,00 sedangkan pada kelompok intervensi dengan alat bantu BBTI dan buku diary diperoleh nilai rata-rata kualitas tidur yang didapatkan dari 12 responden pengukuran sebelum (pre-test) adalah sebesar 7,33 Adapun nilai rata-rata kualitas tidur pengukuran sesudah (post-test) adalah sebesar 5,08 dimana kedua nilai ini menyatakan ada perbedaaan bahwa kelompok yang diintervensi dengan therapy BBT efektif dalam meningkatkan kualitas tidur walaupun tingkat keefektian ini tidak terlalu signifikan karena theapi tersebut therapy prilaku dan komitmen yang terus dilakukan dalam meningkatkan kualitas tidur.

Rata-rata skor PSQI kelompok perlakuan lebih tinggi dari kelompok kontrol hal ini disimpulkan karena dari tujuh komponen yang memepengaruhi kualitas tidur pasien tersebut diantaranya adalah komponen 2 latensi tidur, komponen 3 durasi tidur dan komponen 4 efisiensi tidur, adapun komponen yang sedikit menyumbang skor adalah komponen 6 penggunaan obat-obatan untuk membatasi tidur. Latensi tidur menggambarkan waktu yang diperlukan untuk memulai tidur yang diukur dengan waktu yang dibutuhkan untuk memulai tidur serta frekuensi ketiidakmampuan tidur dalam 30 menit dengan rata durasi dalam penelitian ini 55 menit keadaan tersebut responden kesulitan memulai tidur karena insomnia diakibatkan lelah, dan jantung berdebar-debar, cemas akan penyakitnya. Tidur yang tidak adekuat dan kualitas tidur yang buruk dapat mengakibatkan gangguan 
keseimbangan fisiologi dan psikologi. Kurang tidur selama periode yang lama dapat menyebabkan penyakit lain atau memperburuk penyakit yang ada (Sari et al., 2019).

Durasi tidur menggambarkan lamanya waktu tidur responden rata- rata mengalami pemendekan durasi tidur bahkan ada yang tidak mencapai tidur dalam (REM) ini dikarenakan pasien CHF sering terbatuk pada waktu tidur, dan sering BAK . Pasien CHF efisiensi tidurnya lebih dari $70 \%$ ini dikarenakan gejala fisik seperti sesak, kelelahan dan lingkungan yang tidak nyaman (Hartati, 2019). Komponen BBTI diantaraya stimulus control, sleep restriction, sleep hygiene, cognitive therapy diberikan sesuai dengan kebutuhan responden, buku harian tidur diselesaikan setiap hari selama kontrak penelitian dimulai dengan Base Line penilaian. Sesi I dan sesi 3 terjadi secara langsung dan sesi 2 dan 4 adalah panggilan singkat telpon. BBTI berfokus pada aspek prilaku pengobatan yaitu control stimulus dan pembatasan tidur. Sesi I dan 3 tentang pendidikan terkait fungsi tidur, proses tidur, insomnia, dan kebiasaan yang membantu dan mengganggu tidur dal hal ini peneliti mengajarkan tehnik relaksasi dengan nafas dalam (Syamsiah, 2019).

Prilaku yang direkomendasikan untuk mengatasi gangguan tidur akurat dan ringkas mulai dari kebersihan tidur, mekanisme pengaturan tidur dengan menggunakan buku harian tidur yang dilakukan peneliti dengan pasien dalam sesinya sesi lebih sedikit di sesi 2 dan 4 sleep hygine dan cognitive therapy dimana hasil dari penelitian ini dipengaruhi beberapa hal seperti lingkungan pasien, obat- obatan yang mempengaruhi seperti diuretic (furosemide) dimana pasien sering BAK sehingga mengganggu kualitas tidur responden dan responden juga rata-rata menjawab memulai memulai tidur membutuhkan waktu 15-30 menit. Selain itu juga dipengaruhi oleh pendidikan responden yang mayoritas pendidikan SMP sehingga memerlukan waktu yang lama untuk mengajarkan metode BBTI dan memfokuskan responden untuk menjawab pertanyaan berdasarkan buku harian tidur pasien tersebut.

\section{SIMPULAN}

Bedasarkan hasil penelitian terapi Behavioral Therapy for Insomnia (BBT-I) berpengaruh terhadap kualitas tidur pada pasien CHF (Congestive Heart Failure) dan sesuai dengan hasil riset terkini (Evidence Based Nursing Practice). Studi literature yang didapatkan sebagai bukti ilmiah tentang pasien $\mathrm{CHF}$ dengan gangguan tidur yang dilaksanakan intervensi BBT-I dapat meningkatkan dan mempengaruhi kualitas tidur. Pelaksanaan therapy BBT-I pada pasien CHF grade 1-II dengan gangguan tidur stabil. Pelasanaan therapy BBT-I pada pasien CHF grade I-II stabil dengan gangguan tidur cukup memberikan pengaruh dan meningkat kulitas tidur.

\section{SARAN}

Setelah 4 minggu pelaksanaan terapi BBTI dan evaluasi kepada responden dengan menggunakan instrumen kualitas tidur PSQI maka disarankan bagi pendidikan keperawatan diharapkan bias diajarkan dan diperkenal kan dengan BBTI untuk menambah kompetensi praktik laboratorium. Bagi Pelayananan diharapakan hasil penerapan EBP disosialisasikan kepada staf rumah sakit atau ruangan dan membuat rencana selanjutnya dan diaplikasikan di rumah sakit. Bagi peneliti selanjutnya dapat melanjutkan penelitian ini dengan motode dan jumlah sampel yang berpariasi atau membandingkan dengan intervensi. 


\section{DAFTAR PUSTAKA}

Anggraheni, A. A. (2019). Gambaran Self Care Behaviour pada Pasien Gagal Jantung. Universitas Muhammadiyah Surakarta. http://eprints.ums.ac.id/74938/

Apriliani, K. M., \& Soetjipto, D. (2020). Sleep Disorders in Late-Life Depression. Jurnal Psikiatri Surabaya, 9(1), 1. https://doi.org/10.20473/jps.v9i1.16026

Handayani, L. (2020). Gambaran Kualitas Tidur pada Pasien Gagal Jantung Kanan di RSUD dr. Slamet Garut. Universitas Padjadjaran. http://repository.unpad.ac.id/frontdoor/index/index/docId/35809

Hartati, A. (2019). Gambaran Kualitas Tidur pada Klien Congestif Heart Failure yang Menjalani Rawat Inap di Rumah Sakit Muhammadiyah Bandung. Bhakti Kencana Unversity. http://repository.bku.ac.id/xmlui/handle/123456789/1444

McCrae, C. S., Curtis, A. F., Williams, J. M., Dautovich, N. D., McNamara, J. P. H., Stripling, A., Dzierzewski, J. M., Chan, W. S., Berry, R. B., McCoy, K. J. M., \& Marsiske, M. (2018). Efficacy of Brief Behavioral Treatment for Insomnia in Older Adults: Examination of Sleep, Mood, and Cognitive Outcomes. Sleep Medicine, 51, 153-166. https://doi.org/10.1016/j.sleep.2018.05.018

Riskesdas. (2018). Hasil Utama Riset Kesehatan Dasar. Kementrian Kesehatan Republik Indonesia, 1-100. https://doi.org/https://doi.org/10.1088/17518113/44/8/085201

Sari, P. M., Hasymi, Y., \& Yuseva, M. (2019). Gambaran Kualitas Tidur pada Pasien Gagal Jantung di Ruang ICCU RSUD dr. M. Yunus Bengkulu Tahun 2018. Jurnal Vokasi Keperawatan (JVK), 2(1), 61-71. https://doi.org/10.33369/jvk.v2i1.10655

Syamsiah, A. (2019). Perbedaan Terapi Relaksasi Nafas Dalam dan Terapi Relaksasi Benson terhadap Kualitas Tidur Lansia. Universitas Muhammadiyah Malang. https://eprints.umm.ac.id/52132/

WBP. (2020). Perempuan Lebih Rentan Kena Penyakit Kardiovaskular, Ini Alasannya. https://www.beritasatu.com/kesehatan/595990/perempuan-lebih-rentan-kenapenyakit-kardiovaskular-ini-alasannya 